\title{
Preparation of a solid product with high water content and water reten- tion properties
}

\author{
Marko Cvijicic $^{1,2}$, Janvit Golob ${ }^{1}$ \\ ${ }^{1}$ University of Ljubljana, Faculty of Chemistry and Chemical Technology, Večna pot 113, 1000 Ljubljana, Slovenia \\ ${ }^{2}$ Unichem, Sinja Gorica 2, 1360 Vrhnika, Slovenia \\ "Corresponding authors: e-mail: marko.cvijic@gmail.com; janvit.golob@fkkt.uni-lj.si
}

\begin{abstract}
This work presents the development of a solid product with a high water content $(99.08 \%)$ and water retention properties. Water was chosen as a potential carrier of a volatile active substance and water retaining properties of material were studied at a temperatures and relative air humidity values with the support of the theory of drying. The study first confirmed the role of Gibbs' phase rule in the research of solid-gas phase equilibrium, and second presented drying kinetics developed from Fick's second law and expressed with the first term of the Fourier equation. Solutions of equations for phase equilibrium and mass transfer enabled the calculation of Luikov's parameters, which are important for equilibrium relations and for the diffusivity of water in a solid for mass transfer prediction. The obtained thermodynamic and kinetic parameters enabled product characterisation that may be important for the prediction of retention times.
\end{abstract}

Keywords: water in organic phase emulsion; phase equilibrium; mass transfer; Luikov's parameters; theory of drying.

\section{INTRODUCTION}

Numerous products containing water in organic phase $(\mathrm{W} / \mathrm{O})$ emulsions can be found in different industries, such as the food and cosmetic industries. Most of the research work on these two-phase systems has been focused on the preparation and stability of $\mathrm{W} / \mathrm{O}$ liquid, semi-solid or solid emulsions. Emulsions are thermodynamically unstable systems; therefore, the technical aim of creating "stable emulsions" must be limited to the control of the instability processes such as coalescence, flocculation, creaming, and Ostwald ripening. For the purpose of controlling instability processes two tools are available: the use of mechanical devices to disperse the system, and the addition of stabilising additives, which can be natural or artificial, in order to keep it dispersed ${ }^{1-3}$. The liquid emulsion of water in oil generally presents low stability due to the high mobility of water droplets that can easily sediment, flocculate or coalesce. Therefore, most of the water-in-oil emulsion based products are in a solid or semi-solid state, such as butter and margarine, and are stabilised by fat crystallisation, which prevents the sedimentation of water droplets through the formation of a three-dimensional network ${ }^{4}$.

Additionally, drying plays an important role in understanding and predicting the behaviour of materials. Therefore, the drying of liquid dispersions is one of the most frequently encountered industrial processes in dewatering and thermal treatment. The drying process is inherently a cross- and multi-disciplinary area, which requires the optimal fusion of transport phenomena and material science, since the objective of drying is not only to supply heat and remove moisture from the material but to produce a dehydrated product of specific quality. The quality parameters depend on the product of interest, and what is optimal for heat and mass transfer is typically and unfortunately not optimal from a quality standpoint ${ }^{5}$. However, there is only limited data regarding the analysis of water retaining properties of materials where $\mathrm{W} / \mathrm{O}$ is an intermediate for obtaining a solidified product, especially the thermodynamic equ- ilibrium and kinetics of drying, of this system ${ }^{6}$. If these products are used for several weeks in different weather conditions, the ability to preserve the moisture should be an important feature. Consequently, understanding the water retaining properties of the products seems to be of essential practical significance.

The aim of the presented research work is to create a solid product with high water content through a W/O emulsion intermediate, and with the desired mechanical and applicative properties. Furthermore, this study aims to evaluate water retaining properties of the developed product under different conditions, such as high and low temperatures $(\mathrm{T})$ in relation to high and low relative air humidity (RH), which could have an important impact on product applicability. In addition to characterising the water retaining properties of the product, we also aimed to analyse the effect of additives and paraffin wax on the improvement of mechanical and applicative properties and retaining water. The chemical engineering fundamentals expressed by phase equilibrium, mass transfer and mass balance, in connection with the theory of drying were used to explain the water retaining properties of the product.

\section{MATERIAL AND METHODS}

\section{Raw materials/chemicals}

\section{Components for organic phase preparation}

The role of components added to wax is to retain as much of the dispersed water as possible and to ensure the proper stability of the obtained solid material throughout a wide temperature range. Palm oil (Erapoly Global Sdn, Malaysia) and rapeseed oil (Fediol, Belgia) were used for organic phase preparation. In order to thicken the organic phase, paraffin wax (Himbalt trade, Estonia), beeswax (Shreeji Pharma International, India) and glycerine stearate (World Chem Industries, India) were added. In this phase of preparation, paraffin wax, glycerine stearate and beeswax were also used as emul- 
sifiers and stabilisers. Zinc stearate (Sinwon Industrial Co., Ltd., Korea) was used as a stabiliser of the organic phase for $\mathrm{W} / \mathrm{O}$ phase emulsions ${ }^{7-10}$.

\section{Components for aqueous phase preparation}

Tap water was used as the aqueous phase for emulsion preparation. In order to stabilise and thicken the water phase, magnesium sulphate heptahydrate (Zouping Runzi Chemical Industry Co., Ltd, China), polyethylene glycol (Rimpro India, India) and glycerine (Hangzhou Meite Industry Co., Ltd China) were added ${ }^{7,8}$.

Modified potato starch (Helios Kemostik, d.o.o., Slovenia) was added to the aqueous phase in order to improve physical-chemical (density, viscosity), mechanical (hardness) and thermodynamic (drying) properties of the final product.

Saturated salt solutions to maintain a constant relative air humidity

Sodium chloride (Donauchem GmbH, Austria), lithium chloride (Jigchem Universal, India) and magnesium chloride hexahydrate (Shree Harikrushna Magnesia, India) were used to prepare a saturated salt solution to monitor the drying process in desiccators at a certain RH $(11 \%, 32 \%$ and $75 \%)$ and $\mathrm{T}\left(40^{\circ} \mathrm{C}\right)^{11,12}$.

\section{Emulsion preparation}

The emulsion was prepared in three stages: first, the organic phase (Step 1) and the aqueous phase (Step 2) were prepared separately, then both phases were mixed together (Step 3) to get a W/O emulsion that serves as an intermediate to obtain the final product. The $\mathrm{T}$ rise was set depending on the melting point of the additives and the mixing speed was increased as high as possible in order to disperse the water phase.

Step 1: The organic phase was prepared by mixing palm oil $(253.40 \mathrm{~g})$ and rapeseed oil $(54.20 \mathrm{~g})$ using an IKA RW16 basic propeller stirrer (IKA - Werke GmbH \& Co. KG, Germany) at $500 \mathrm{rpm}$ and heating the mixture to $40^{\circ} \mathrm{C}$ for 10 minutes with Heidolph MR Hei-End (Heidolph Instruments $\mathrm{GmbH} \& \mathrm{Co} . \mathrm{KG}$, Germany). When a homogenous mixture was obtained, beeswax (3.28 g) was added. The mixture was heated to $60^{\circ} \mathrm{C}$ and paraffin wax $(42.93 \mathrm{~g})$ was added. When the paraffin wax had melted entirely, the propeller stirrer was set to $1000 \mathrm{rpm}$ and glycerine stearate $(26.71 \mathrm{~g})$ was added slowly. The organic phase was mixed until all the glycerine stearate was dissolved and no lumps were detected. Then, zinc stearate $(21.32 \mathrm{~g})$ was added and the propeller stirrer was set to $1500 \mathrm{rpm}$ and the $\mathrm{T}$ of the mixture was raised to $70^{\circ} \mathrm{C}$. When the zinc stearate had dissolved completely, the propeller stirrer was set to $2500 \mathrm{rpm}$ and the $\mathrm{T}$ was raised to $85^{\circ} \mathrm{C}$.

Step 2: Magnesium sulphate heptahydrate (12.29 g) was added to the water $(491.4 \mathrm{~g})$ heated to $40^{\circ} \mathrm{C}$ and stirred using a propeller stirrer set to $1000 \mathrm{rpm}$. When the salt had dissolved in the water, glycerine $(9.83 \mathrm{~g})$ and polyethylene glycol $(25.68 \mathrm{~g})$ were added to the mixture. The mixture was slowly heated to $55^{\circ} \mathrm{C}$ and stirred while being heated using a propeller stirrer set to $5000 \mathrm{rpm}$. When the set $\mathrm{T}$ point was reached, modified potato starch $(58.97 \mathrm{~g})$ was added. After all the potato starch had dissolved, the $\mathrm{T}$ was raised to $85^{\circ} \mathrm{C}$.
Step 3: When the set $\mathrm{T}$ of both organic and aqueous phase was reached, the propeller stirrer was replaced with a gate blade stirrer and the water phase was added slowly to the organic phase. An IKA T-25 digital ultra turrax rotor-stator stirrer (IKA - Werke GmbH \& Co. KG, Germany) was used for 60 seconds at 20,000 rpm for homogenisation and emulsion preparation. Following the dispersing procedure (when the solution became white), the heating was turned off. The cooling process consisted of two steps lasting one hour in total. The first step was performed under agitating condition and the second one without. The cooling phase to room $\mathrm{T}$ started with the gate blade stirrer set at $500-1000 \mathrm{rpm}$. After reaching the desired viscosity at a $\mathrm{T}$ between $30-40^{\circ} \mathrm{C}$, the stirrer was stopped, and cooling continued at room $\mathrm{T}$ until the $\mathrm{W} / \mathrm{O}$ emulsion intermediate reached a solid phase state.

\section{Characterisation of the emulsion intermediate}

The evaluation of the emulsion type and determination of the physical properties of the solidified product

After the end of emulsification process of intermediate preparation, the emulsion type was determined by a simple drop test, which analysed what happened when a drop of prepared emulsion was added to a volume of either organic phase or pure water. When drops of water-in-oil emulsion are dispersed in oil they remain as drops in water. On the other hand, if the emulsion is an oil-in-water emulsion and drops of emulsion are dispersed in water they remain as drops in oil ${ }^{13}$.

Physical properties such as the density and viscosity of the emulsion intermediate were measured at a $\mathrm{T}$ between 40 and $50^{\circ} \mathrm{C}$. The density was measured by pouring the product into a measuring cylinder up to a specific volume mark. The measuring cylinder was put on an analytical scale. The density was then calculated from the volume and mass of the sample in the measuring cylinder. The viscosity was measured using a measuring cylinder and a ball. The time needed by the ball to travel from one point to another in the cylinder was measured. From the obtained data and considering the properties of the medium and the ball, the viscosity was then calculated.

Viscosity was calculated using the following equation:

$v=\left[2\left(\rho_{s^{-}} \rho_{l}\right) g a^{2}\right] / 9 v$

where $\varrho_{s}$ is the density of the sphere, $\varrho_{1}$ is the density of the medium, $\mathbf{g}$ is the acceleration due to gravity, $\mathbf{a}$ is the radius of the sphere, and $\mathbf{v}$ is the velocity of the sphere.

\section{Droplet size measurement and distribution}

The particle size and distribution of water droplets in the organic phase were analysed using the Microtrac S3500 Particle Size analyser, Microtrac sample delivery controller (SDC) and Microtrac Flex 11 software (Nikkiso Co., Ltd, Japan). The analysis of the size of droplets was performed on two samples, which were prepared at different speed rates using a rotor-stator stirrer. One sample was prepared at $5000 \mathrm{rpm}$ and the second one at $20,000 \mathrm{rpm}$ in order to evaluate the difference in droplet size at different mixing speeds. 


\section{Characterisation of the solid product}

The evaluation of the water retaining properties of the solidified product

At first, the samples of the analysed material were placed into Petri dishes in order to obtain samples with the same dimensions (diameter and thickness of the layer). Evaluation of the product's water retaining properties, expressed as the phase equilibrium between moisture content (MC) and air humidity, were determined by using a standard approach with saturated salt solutions in desiccators and in a climate chamber ${ }^{\mathbf{1 2}}$. For the first procedure, a Kambic SP 45 C dryer (Kambič d.o.o., Slovenia) was used, where the $\mathrm{T}$ was regulated automatically, while $\mathrm{RH}$ was maintained with saturated saline solutions at a certain RH (11, 32 and 75\%). A PKK-125 ER Kambic climate chamber was used in the second procedure, where T and RH (32\%) were set and automatically regulated during the process.

In addition to determining the water retention capacity at various conditions, another objective was to determine the impact of additives used and the amount of paraffin wax added. For this purpose, different samples without additives (beeswax, glycerine stearate, magnesium sulphate heptahydrate, polyethylene glycol, glycerine and modified potato starch) and with a different content of paraffin wax $(2.30,4.30$ and $23.07 \%)$ were prepared. An additional objective was to examine the effect of the absence of additives and of the lower or higher content of paraffin wax on water retention (at $40^{\circ} \mathrm{C}$ and with a $\mathrm{RH}$ of $32 \%$ in a 6- to 7-day period) compared to the developed product.

The water retaining properties of the examined product were assessed by using the theory of drying, combining the knowledge of thermodynamics regarding equilibrium data and mass transfer phenomena connected with drying kinetics. In this case, water retention time is one of the most important factors and is used along with the theory of drying for the development of a mathematical model needed for the prediction of a product's behaviour and characterisation.

\section{Model for material characterisation}

\section{Thermodynamic - phase (solid - gas) equilibrium}

The measurements of pairs MC of material $(\mathbf{X})$ and $\mathrm{RH}(\boldsymbol{\varphi})$ at a chosen $\mathrm{T}$ and air pressure $(\mathbf{P})$ enabled the computation of Luikov's parameters $\left(\mathbf{X}_{\max }, \mathbf{a}\right)^{15}$. The equilibrium data, or more precisely the pseudo-equilibrium data, were calculated using Equation 2, where Gibbs' phase rule aids in understanding the situation for a system with three components (air, water, solid material) and two phases (solid material, air), which describes the relation between $\boldsymbol{\varphi}$ and $\boldsymbol{X}$ at constant $\boldsymbol{T}$ and $\mathbf{P}$ :

$\ln \varphi=\frac{1}{a}\left(\frac{1}{X \max }-\frac{1}{X}\right)$

where: $\boldsymbol{\varphi}$ - relative air humidity; $\mathbf{X}-\mathrm{MC}$ of material; $\mathbf{X}_{\max }-$ MC of material at $\boldsymbol{\varphi}=1(100 \%) ; \mathbf{a}-$ Luikov's parameter at a chosen $\mathrm{T}$.
Water retaining properties studied through drying kinetics (mass transfer)

The water retaining properties of the product were assessed by measuring the MC of the material over time. For this purpose, the theory of the diffusion of water through solids was used. Drying kinetics under unsteady state conditions showing the relation between $\mathrm{MC}$ of the material depending on time are expressed by the first term of the Fourier equation developed from Fick's second law:

$\frac{\partial c}{\partial t}=D \frac{\partial^{2} c}{\partial z^{2}}$

Concentration $\mathbf{c}$ can be converted into $\mathbf{X}$ to solve the partial differential equation, where the following dimensionless variables are introduced:

$\mathrm{Y}=\frac{c-c_{e}}{c_{0}-c_{e}}$

Boundaries and initial conditions:

$\mathrm{t}=0 ; \mathrm{X}=\mathrm{X}_{0} ; \mathrm{Y}=1 ; \mathrm{X}_{\mathrm{D}}=0$

$\mathrm{t}=\infty ; \mathrm{X}=\mathrm{X}_{\mathrm{e}} ; \mathrm{Y}=0 ; \mathrm{X}_{\mathrm{D}}=\infty$

$\mathrm{X}_{\mathrm{D}}$ represents an analogue to the Fourier number (Fo) and is equal to: $\mathrm{X}_{\mathrm{D}}=\frac{D t}{z_{1}^{2}}$ The solution is the Fourier series, where the first term was used as a sufficiently accurate approach for engineering purposes:

$\frac{X-X_{e}}{X_{0}-X_{e}}=\frac{4}{\pi} \exp ^{-\left[\frac{\pi^{2}}{4} \frac{D t}{z_{1}^{2}}\right]}$

where: $\mathbf{X}-\mathrm{MC}$ of the material after a certain time; $\mathbf{X}_{\mathbf{0}}$ - initial MC of the material; $\mathbf{X}_{\mathrm{e}}$ - pseudo-equilibrium moisture content (EMC); D - diffusivity; $\mathbf{z}_{\mathbf{1}}$ - thickness layer of the sample; $\mathbf{t}$ - time.

Therefore, the measurements of pair $X, t$ at chosen $X_{e}$, $\boldsymbol{X}_{\boldsymbol{0}}, \boldsymbol{z}$ values, obtained with the experiment, enabled us to calculate the diffusivity of water in a solid material where the surface material $\mathrm{MC}$ is constant. ${ }^{17}$

\section{RESULTS AND DISCUSSION}

The experiment enabled us to prepare a solid product with a high water content, and to analyse its water retaining properties under different $\mathrm{T}$ and humidity conditions. Additionally, the aim to have a high share of aqueous phase in the product was reached and, by using different process techniques and a variety of additives, the obtained ratio between aqueous and organic phase was almost 1:1. Additives to the organic and aqueous phases ensure us the required mechanical and applicative properties of the solid product and are expressed by retaining water and usability criteria, which are dependent on time, $\mathrm{T}$ and RH. As the product development was designed considering the possibility of recycling the product, the main challenge was to use as many raw materials as possible that were classified as food grade.

\section{Characterisation of the emulsion intermediate}

The evaluation of the emulsion type and physical properties

Drops of the prepared emulsion remained as drops in water. Therefore, it can be concluded that the intermediate of developed preparation was a W/O emulsion.

The density of the obtained product measured at a $\mathrm{T}$ between 40 and $50^{\circ} \mathrm{C}$ was in the range from 0.80 
to $0.85 \mathrm{~g} / \mathrm{ml}$ and the viscosity in the range from 8.5 to $9 \mathrm{~kg} / \mathrm{ms}$ (Pas). The density of the sphere with which the viscosity was calculated was $20.5 \mathrm{~g} / \mathrm{ml}$ and its radius was $0.02 \mathrm{~m}$. The velocity of the sphere was between $0.0019 \mathrm{~m} / \mathrm{s}$ and $0.0020 \mathrm{~m} / \mathrm{s}$.

Additives to the wax ensured the desired properties of solid material, expressed by hardness, solid state criterium, density and $\mathrm{T}$.

\section{Droplet size measurement and distribution}

The analysis of the size of droplets is an important factor when studying the water retention of a material with the theory of drying. As presented in Figure 1, the higher stirring speed contributed to a larger proportion of drops with a smaller diameter. The droplets in the prepared samples were in the micron range of particle size, which means that, in this case, droplets consisted of thousands of water molecules unified in clusters. on determining the water retaining properties based on the theory of drying, which are the most important criteria for long-term use in dry and high $\mathrm{T}$ specific humid conditions.

\section{Model for material characterisation}

The water retaining properties of the product assessed by saturated salt solutions in desiccators

The water retaining properties of the obtained solid product were measured at $40^{\circ} \mathrm{C}$ at $11 \%, 32 \%$ and $75 \%$ $\mathrm{RH}$ using saturated salt solutions in desiccators and at $20^{\circ} \mathrm{C}$ at $32 \% \mathrm{RH}$ in climate chamber ${ }^{11,}{ }^{18}$. At each $\mathrm{RH}$ three samples were taken. For the calculations, the average value of all three samples was used. Every 2 to 3 days the samples were weighed to record their change in mass. The retaining of water in the product was observed until the pseudo-equilibrium state of the material

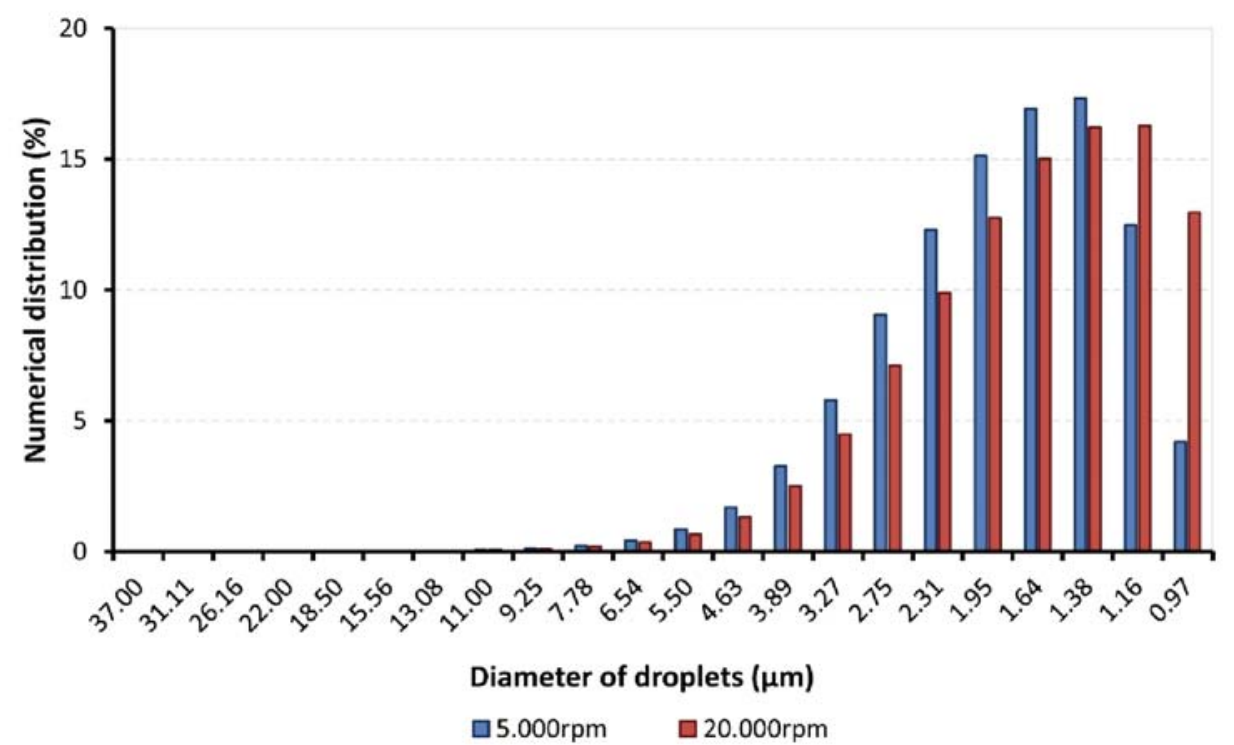

Figure 1. Comparisation of droplet size and numerical distribution at different stirring rates

\section{Characterisation of the solid product}

The evaluation of the water retaining properties of the solidified product

An important aim of this study was to find the proper ratio of $\mathrm{W} / \mathrm{O}$ (the highest water content as possible) in order to establish the acceptable mechanical and applicative properties of the solid product, especially when exposed to different conditions, such as $\mathrm{RH}$ and T. The percentage of water in the formulated product was $49.77 \%$, which equates to a ratio between aqueous phase and organic material of almost 1:1. The initial $\left(\mathbf{X}_{\mathbf{0}}\right)$ and end $(\mathbf{X})$ moistteure content of the material were calculated using following equation:

$\mathrm{X}=\mathrm{m}_{\text {water }} / \mathrm{m}_{\text {organic phase }}$

where $m_{\text {water }}$ is the mass of water in the product and $\mathrm{m}_{\text {organic material }}$ is the mass of dry organic material in the product.

The use of an appropriate technique is essential to maintain the solid product and to establish the planned ratio in the water-organic phase. Having achieved the optimal $\mathrm{W} / \mathrm{O}$ ratio to get a stable product with the desired mechanical properties, the study was focused was achieved. Table 1 presents the measured value of the mass of the product obtained with the experiment at different $\mathrm{T}$ and $\mathrm{RH}$ and its calculated MC, whereas Figure 2 shows the changing of the $\mathrm{MC}$ of the material over time at $40^{\circ} \mathrm{C}$ and different $\mathrm{RH}$.

Figure 2 shows the impact of different $\mathrm{RH}$ on the product at a constant $\mathrm{T}$. At higher $\mathrm{RH}$, the pseudoequilibrium state is achieved faster than at lower humidity. Based on the results, it is expected that at a constant $\mathrm{T}$

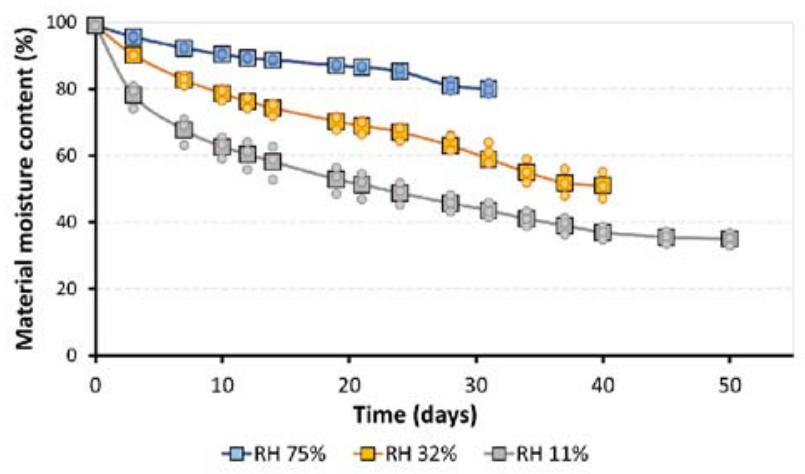

Figure 2. Material moisture content over time at temperature $40^{\circ} \mathrm{C}$ and different relative air humidity $(\mathrm{RH})$ values 
Table 1. Experimental results obtained with drying the product at $20^{\circ} \mathrm{C}$ and $40^{\circ} \mathrm{C}$ at different relative air humidity with saturated salt solutions

\begin{tabular}{|c|c|c|c|c|c|c|}
\hline \multicolumn{7}{|c|}{ Temperature: $20^{\circ} \mathrm{C}$} \\
\hline \multicolumn{7}{|c|}{ Relative air humidity: $32 \%$} \\
\hline $\mathrm{m}_{\text {sample }}(\mathrm{g})$ & $\mathrm{m}_{0}$ water $(\mathrm{g})$ & $m_{\text {organic material }}(\mathrm{g})$ & $m_{k \text { water }}(g)$ & $\mathrm{t}$ (day) & $\mathrm{X}_{0 \text { material }}(\%)$ & $\mathrm{X}_{\mathrm{e} \text { material }}(\%)$ \\
\hline 73.67 & 36.66 & 37.01 & 16.92 & 52 & 99.08 & 45.70 \\
\hline \multicolumn{7}{|c|}{ Temperature: $40^{\circ} \mathrm{C}$} \\
\hline \multicolumn{7}{|c|}{ Relative air humidity: $75 \%$} \\
\hline $\mathrm{m}_{\text {sample }}(\mathrm{g})$ & $\mathrm{m}_{0}$ water $(\mathrm{g})$ & $\mathrm{m}$ organic material $(\mathrm{g})$ & $m_{k}$ water $(g)$ & $\mathrm{t}$ (day) & $\mathrm{X}_{0 \text { material }}(\%)$ & $\mathrm{X}_{\mathrm{e} \text { material }}(\%)$ \\
\hline 69.32 & 34.50 & 34.82 & 27.87 & 31 & 99.08 & 80.03 \\
\hline \multicolumn{7}{|c|}{ Relative air humidity: $32 \%$} \\
\hline $\mathrm{m}_{\text {sample }}(\mathrm{g})$ & $\mathrm{m}_{0}$ water $(\mathrm{g})$ & $\mathrm{m}_{\text {organic material }}(\mathrm{g})$ & $\mathrm{m}_{\mathrm{k} \text { water }}(\mathrm{g})$ & $\mathrm{t}$ (day) & $\mathrm{X}_{0 \text { material }}(\%)$ & $\mathrm{X}_{\mathrm{e} \text { material }}(\%)$ \\
\hline 78.60 & 39.12 & 39.48 & 20.14 & 40 & 99.08 & 51.00 \\
\hline \multicolumn{7}{|c|}{ Relative air humidity: $11 \%$} \\
\hline $\mathrm{m}_{\text {sample }}(\mathrm{g})$ & $m_{0 \text { water }}(\mathrm{g})$ & $m_{\text {organic material }}(\mathrm{g})$ & $m_{k \text { water }}(g)$ & $t$ (day) & $\mathrm{X}_{0 \text { material }}(\%)$ & $\mathrm{X}_{\mathrm{e} \text { material }}(\%)$ \\
\hline 74.05 & 36.85 & 37.20 & 13.02 & 50 & 99.08 & 35.00 \\
\hline
\end{tabular}

$\mathrm{m}_{\text {sample }}$ - initial mass of sample, $\mathrm{m}_{0}$ water - initial mass of water in the sample, $\mathrm{m}_{\text {organic material }}-$ initial mass of dry organic matter, $\mathrm{m}_{\mathrm{k}}$ water $-\mathrm{mass}$ of the water in sample after reaching pseudo-equilibrium state, $\mathrm{t}$ - time for reaching pseudo-equilibrium state, $\mathrm{X}_{0}$ material - initial moisture content in material, $\mathrm{X}_{\mathrm{e} \text { material }}$ - moisture content of material at pseudo-equilibrium state.

the product will retain the corresponding properties at a higher $\mathrm{RH}$ for a longer period than at a lower $\mathrm{RH}$.

The behaviour of the material at $20^{\circ} \mathrm{C}$ and $\mathrm{RH} 32 \%$ is presented in Figure 3. Comparing data from Figure 2 and Figure 3 shows that at the same RH the material's water retaining ability is better at a lower $\mathrm{T}$. This can be an important piece of information in understanding the behaviour of a studied material under different conditions.

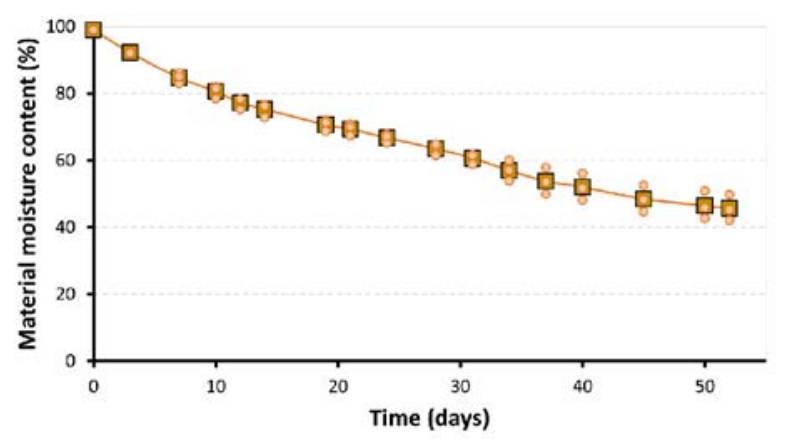

Figure 3. Material moisture content over time at temperature $20^{\circ} \mathrm{C}$ and $32 \%$ relative air humidity $(\mathrm{RH})$

The experiment was designed in a way where two variables, time $(\mathrm{t})$ and EMC of the material $\left(\mathrm{X}_{\mathrm{e}}\right)$, were used as a basis. These two variables were then used in the first term of the Fourier equation for calculating diffusivity (D) and for calculating Luikov's parameters (a and $\mathrm{X}_{\max }$ ) using the Luikov equation.

Diffusivity (D) was calculated using Equation 4, from which $\boldsymbol{D}$ was derived:

$D=\frac{4 z_{1}^{2}}{t \pi^{2}} \ln \left(\frac{4}{\pi} \frac{X_{0}-X_{e}}{X-X_{e}}\right)$

Since the material was in a Petri dish, where the thickness of the layer was $15 \mathrm{~mm}$, diffusivity was only possible in one direction. In order to calculate the diffusivity of the material from Equation 6, value $\mathrm{X}$ needs to be higher than $\mathrm{X}_{\mathrm{e}}$. To obtain the $\mathrm{X}$ value, the value $\mathrm{X}_{\mathrm{e}}$ was increased by $1 \%$. After the equilibrium on the surface is reached, which is presumed to occur instantly after the start of the process, the surface concentration is equal throughout the entire process of drying. Therefore, our system is considered as a system where surface conditions remain constant, which is also a condition for using Equation 4.

The calculated diffusivity values of the developed product are presented in Table 2. According to the literature, the order of the magnitude of the diffusion classifies our product as a solid material ${ }^{15}$.

Additional water retaining properties of the product were determined using the measured data on the RH, T, time and mass, using Luikov's relation to compute the EMC and further by using the first term of the Fourier equation to obtain the drying rate of a solid product under different conditions.

The final goal of the study is to predict the time of moisture retainment in the developed solid material. For this purpose, the first step is to create a simple mathematical model from the fundamentals of chemical engineering to obtain the basic retainment properties of diffusivity and Luikov's parameter a, and the second step is to calculate the relevant time of usability under the provided conditions.

$t=\frac{4 z_{1}^{2}}{D \pi^{2}} \ln \left(\frac{4}{\pi} \frac{X_{0}-X_{e}}{X-X_{e}}\right)$

A sorption isotherm was obtained from the calculation of $\boldsymbol{X}$ at different $\boldsymbol{R} \boldsymbol{H}$ at $40^{\circ} \mathrm{C}$. The experimentally obtained measurements of final $\boldsymbol{X}$ values of the samples obtained at different $\boldsymbol{\varphi}$ are presented in Table 3.

Table 3. Relation between relative air humidity and material moisture content

\begin{tabular}{|c|c|}
\hline $\begin{array}{c}\text { Relative air humidity }(\varphi) \\
(\%)\end{array}$ & $\begin{array}{c}\text { Pseudo equilibrium moisture content of } \\
\text { material }\left(X_{\mathrm{e}}\right)(\%)\end{array}$ \\
\hline 100 & 99.08 \\
\hline 75 & 80.03 \\
\hline 32 & 51.00 \\
\hline 11 & 35.00 \\
\hline 0 & 0 \\
\hline
\end{tabular}

Table 2. Calculation of final material moisture content $(\mathrm{X})$ and diffusivity of the material (D) at temperature $20^{\circ} \mathrm{C}$ and $40^{\circ} \mathrm{C}$ at different relative air humidity with saturated salt solutions where $\mathrm{z}_{1}$ is $15 \mathrm{~mm}$

\begin{tabular}{|c|c|c|c|c|c|c|c|}
\hline \multicolumn{6}{|c|}{ Temperature: $40^{\circ} \mathrm{C}$} & \multirow{2}{*}{\multicolumn{2}{|c|}{$\begin{array}{c}\text { Temperature: } 20^{\circ} \mathrm{C} \\
\text { Relative air humidity: } 32 \%\end{array}$}} \\
\hline Relative a & midity: $75 \%$ & Relative a & midity: $32 \%$ & Relative a & umidity: $11 \%$ & & \\
\hline $\mathrm{X}_{\text {material }}(\%)$ & $\mathrm{D}\left[\mathrm{m}^{2} / \mathrm{s}\right]$ & $\mathrm{X}_{\text {material }}(\%)$ & $\mathrm{D}\left[\mathrm{m}^{2} / \mathrm{s}\right]$ & $\mathrm{X}_{\text {material }}(\%)$ & $\mathrm{D}\left[\mathrm{m}^{2} / \mathrm{s}\right]$ & $\mathrm{X}_{\text {material }}(\%)$ & $\mathrm{D}\left[\mathrm{m}^{2} / \mathrm{s}\right]$ \\
\hline 80.83 & $11.63 \times 10^{-11}$ & 51.50 & $12.68 \times 10^{-11}$ & 35.35 & $11.52 \times 10^{-11}$ & 46.16 & $10.16 \times 10^{-11}$ \\
\hline
\end{tabular}




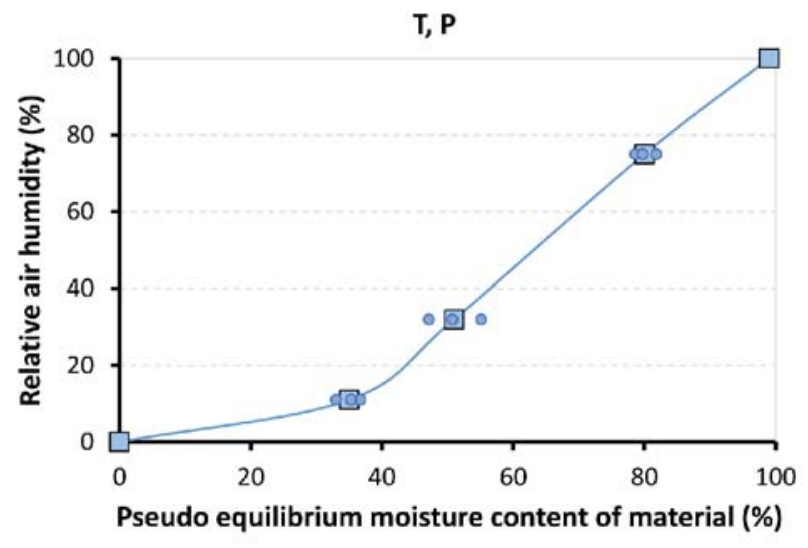

Figure 4. Sorption isotherm for the product obtained with experimental results at $40^{\circ} \mathrm{C}$

These $\boldsymbol{\varphi}$ and $\boldsymbol{X}$ pairs served as the basis for the determination of the sorption isotherm and are presented in Figure 4.

The sorption isotherm obtained from the measurements of our developed solid product (Fig. 4) is very similar to the theoretical sorption isotherms for high hygroscopic materials ${ }^{19}$. Therefore, it can be concluded that the developed product has the same properties as high hygroscopic materials. From Figure 4, Luikov parameters $\boldsymbol{a}$ and $\boldsymbol{X}_{\max }$ can be graphically obtained and confirm the correctness of the values obtained with calculations. Value $\boldsymbol{a}$ is defined as the slope of the curve, and $\boldsymbol{X}_{\max }$ as the value at $\boldsymbol{\varphi}=1$.

For each humidity value, a sorption isotherm indicates the corresponding water content value at a given constant $\mathrm{T}$. If the composition or quality of the material changes, then its sorption behaviour also changes. Because of the complexity of sorption processes, the isotherms cannot be determined by calculations, but must instead be recorded experimentally for each product ${ }^{20}$.

Luikov's parameter a for the product was obtained by a calculation by using Equation 2 and values of pair $\boldsymbol{X}_{\max }, \boldsymbol{\varphi}_{0}$ and $\boldsymbol{X}, \boldsymbol{\varphi}$ of the product from Table 1. The values of Luikov's parameters for different $\boldsymbol{R} \boldsymbol{H}$ and $\boldsymbol{X}$ are presented in Table 4.

$a=\left(\frac{1}{X \max }-\frac{1}{X}\right) / \ln \varphi$

The obtained corresponding water retaining properties of the product were reached and are expressed with unique Luikov's parameters (Table 4) and with diffusivity as a critical parameter (Table 2).

In addition to characterising the developed solid material with the properties described above, we aimed to also analyse the role of additives in the preparation process and their impact on the improvement of retaining water. For this purpose, different samples were prepared without additives (without beeswax, magnesium sulphate heptahydrate, glycerine, polyethylene glycol and modified potato starch) and with different amounts of paraffin
Table 5. A list of samples according to the paraffin content and the additives used

\begin{tabular}{|l|c|c|}
\hline & $\begin{array}{c}\text { Amount of paraffin wax } \\
(\%)\end{array}$ & $\begin{array}{c}\text { Additives used } \\
\text { (Yes/No) }\end{array}$ \\
\hline Sample 1 & 2.30 & No \\
\hline Sample 2 & 4.30 & No \\
\hline Sample 3 & 23.07 & No \\
\hline $\begin{array}{l}\text { Material under the } \\
\text { study }\end{array}$ & 4.30 & Yes \\
\hline
\end{tabular}

wax as shown in Table 5. The MC of the samples was analysed over a 6- to 7-day period at a $\mathrm{T}$ of $40^{\circ} \mathrm{C}$ and a RH of $32 \%$ and compared with the developed solid material (Fig. 5). As can be seen from Figure 5, there

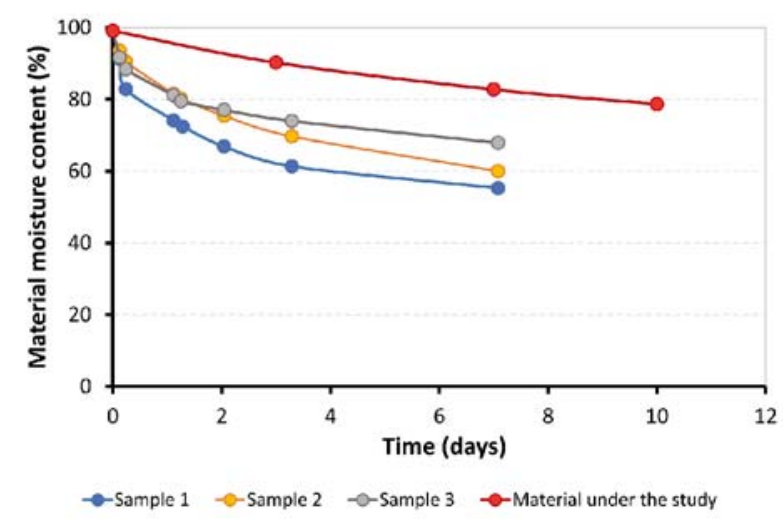

Figure 5. Moisture content of material and samples over time at temperature $40^{\circ} \mathrm{C}$ and relative air humidity $(\mathrm{RH})$ $32 \%$

are noticeable differences between the samples without additives and the material under consideration.

The obtained results show that paraffin wax has a significant effect on water retention since the retention capacity is poorer in the case of a smaller amount (Sample 1) and better in the case of a larger amount (Sample 3) of added paraffin wax. With a higher content of paraffin wax, the hardness of the material also increases. This is important information in situations where not only good water retention but also other physical properties of material are desired. Comparing the experimentally obtained data shows that additives have a similar effect on water retention as paraffin wax. When comparing Sample 2 with the material under investigation, where both have the same amount of paraffin wax, the results show that additives have a significant impact on the ability of a material to retain water (Fig. 5).

\section{CONCLUSION}

The development of a solid product with specific physical and chemical properties and a high water content was achieved. In the analysis of water retaining properties,

Table 4. Calculations of Luikov parameter a for the product at different $\varphi$ and $X$

\begin{tabular}{|c|c|c|c|c|}
\hline $\begin{array}{l}\text { Maximum material moisture content } \\
\qquad\left(\mathrm{X}_{\max }\right)\end{array}$ & $\begin{array}{c}\text { Maximum relative air } \\
\text { humidity } \\
\left(\varphi_{0}\right)\end{array}$ & $\begin{array}{l}\text { Pseudo equilibrium moisture } \\
\text { content } \\
\left(\mathrm{X}_{\mathrm{e}}\right)\end{array}$ & $\begin{array}{l}\text { Relative air } \\
\text { humidity } \\
(\varphi)\end{array}$ & $\begin{array}{l}\text { Luikov } \\
\text { parameter } \\
\text { (a) }\end{array}$ \\
\hline 99.08 & 100 & 80.03 & 75 & 0.84 \\
\hline 99.08 & 100 & 51.00 & 32 & 0.84 \\
\hline 99.08 & 100 & 35.00 & 11 & 0.84 \\
\hline
\end{tabular}

$\mathrm{X}_{\max }$ is defined as value at $\varphi=1$ 
time and EMC of the material were taken as a basis. Equilibrium data were explained with Gibbs' phase rule and used in Luikov's equation to get Luikov's parameter a. As diffusivity determines the usability timeframe of the product and Luikov's parameters are specific to each material, the presented simplified mathematical model may enable the prediction of how long the product will retain adequate moisture under certain conditions. Therefore, the presented results could be applied to a variety of products where the retention of water affects the product's usability.

\section{Declarations of interest: none}

\section{LITERATURE CITED}

1. Bergenståhl, B. \& Claesson, P.M. (1997). Surface forces in emulsions. In K. \& F. Larsson S. (Ed.), Food Emulsions (3rd ed., pp. 57-109). YKI - Ytkemiska institutet: Marcel Dekker.

2. Drelich, A., Gomez, F., Clausse, D. \& Pezron, I. (2010).

Evolution of water-in-oil emulsions stabilized with solid particles: Influence of added emulsifier. Colloids Surfaces A Physicochem. Eng. Asp. 365, 171-177. DOI: 10.1016/j.colsurfa.2010.01.042.

3. Li, C., Mei, Z., Liu, Q., Wang, J., Xu, J. \& Sun, D. (2010). Formation and properties of paraffin wax submicron emulsions prepared by the emulsion inversion point method. Colloids Surfaces A Physicochem. Eng. Asp. 356(1-3), 71-77. DOI: 10.1016/j.colsurfa.2009.12.036.

4. Ushikubo, F.Y. \& Cunha, R.L. (2014). Stability mechanisms of liquid water-in-oil emulsions. Food Hydrocoll. 34, 145-153. DOI: 10.1016/j.foodhyd.2012.11.016.

5. Mujumdar, A.S. (2004). Research and development in drying: Recent trends and future prospects. Dry. Technol. 22(1-2), 1-26. DOI: 10.1081/DRT-120028201.

6. Connick, W., Daigle, D. \& Quimby, P. (1991). An Improved Invert Emulsion with High Water Retention for Mycoherbicide Delivery. Weed Technology 5(2), 442-444. DOI: 10.1017/S0890037X00028402.
7. Williams, S.D. \& Schmitt, W.H. (Ed.). (1992). Chemistry and Technology of the Cosmetics and Toiletries Industry (1st ed.). Springer Netherlands.

8. Klein, K. (2003). Formulating Water-in-Oil Emulsions: A Scary Endeavor, 118, 24-25.

9. Williams, D.F. (2002). The chemistry and manufacture of cosmetic (Volume III).

10. Binks, B.P. \& Rocher, A. (2009). Effects of temperature on water-in-oil emulsions stabilised solely by wax microparticles. J. Colloid Interf. Sci. 335(1), 94-104. DOI: 10.1016/j. jcis.2009.03.089

11. Greenspan, L. (1977). Humidity fixed points of binary saturated aqueous solutions. J. Res. Natl. Bur. Stand., A Phys. Chem. 81A(1), 89. DOI: 10.6028/jres.081A.011

12. Young, J.F. (1967). Humidity control in the laboratory using salt solutions. J. Appl. Chem. 17(September), 241-245.

13. Henríquez, C.J.M. (2009). W/O Emulsions: Formulation, Characterization and Destabilization. Doctoral thesis. Brandenburgische Technische Universität Cottbus, Fakultät fur Umweltwissenschaften und Verfahrenstechnik. http://opus4. kobv.de/opus4-btu/frontdoor/deliver/index/docId/471/file/genehmigte_Diss_Morales.pdf.

14. Webster, J.G. (Ed.). (1999). The measurement, instrumentation and sensors (1st ed.). CRC Press LLC.

15. Keey, R.B. (1978). Introduction to Industrial Drying Operations. Pergamon Press.

16. Babbitt, J.D. (1950). On the differential equations of diffusion. Can J. Res. 28(2172), 449-474. DOI: 10.1139/cjr50a-037

17. Crank, J. (1975). The Mathematics of Diffusion (2nd ed.). Clarendon Press.

18. Wexler, A. \& Hasegawa, S. (1954). Relative humiditytemperature relationships of some saturated salt solutions in the temperature range 0 degree to 50 degrees C. J. Res. Natl. Bur. Stand. 53(1), 19-26. DOI: 10.6028/jres.053.003.

19. Keey, R.B. (1972). Drying principles and practice. Pergamon Press.

20. Bell, L.N. \& Labuza, T.P. (2000). Practical Aspects of Moisture Sorption Isotherm Measurement and Use (2nd ed.). AACC Eagan Press. 